\title{
The role of gill raker number variability in adaptive radiation of coregonid
}

fish

\author{
Kimmo K. Kahilainen ${ }^{1,2 *}$, Anna Siwertsson ${ }^{3}$, Karl Ø. Gjelland ${ }^{3}$, Rune Knudsen ${ }^{3}$, \\ Thomas Bøhn ${ }^{3,4}$ and Per-Arne Amundsen ${ }^{3}$ \\ ${ }^{1}$ Department of Environmental Sciences, University of Helsinki, P.O. Box 65, FI-00014 \\ Finland, ${ }^{2}$ current address: Kilpisjärvi Biological Station, University of Helsinki,
}

Käsivarrentie 14622, FI-99490 Kilpisjärvi, Finland

${ }^{3}$ Department of Arctic and Marine Biology, Faculty of Biosciences, Fisheries and Economics, University of Tromsø, N-9037 Tromsø, Norway

${ }^{4}$ GenØk-Centre for Biosafety, The Science Park, P.O. Box 6418, N-9294 Tromsø, Norway

* Author for correspondence (kimmo.kahilainen@helsinki.fi)

Running title: Gill rakers and adaptive radiation of coregonid fish

Keywords: ecological speciation, foraging trait, polymorphism, vendace, whitefish morphs

Total word count (excluding references, tables and figures): 5401 words

Abstract: 202 words

Introduction: 1047 words

Materials and methods: 1513 words

Results: 515 words

Discussion: 1836 words

Acknowledgments: 137 words

Number of references: 73

Number of tables and figures: 8 


\section{ABSTRACT}

Gill raker divergence is a general pattern in adaptive radiations of postglacial fish, but few studies have addressed the adaptive significance of this morphological trait in foraging and eco-evolutionary interactions among predator and prey. Here, a set of subarctic lakes along a diversifying gradient of coregonids was used as the natural setting to explore correlations between gill raker numbers and planktivory as well as the impact of coregonid radiation on zooplankton communities. Results from 19 populations covering most of the total gill raker number gradient of the genus Coregonus, confirm that the number of gill rakers has a central role in determining the foraging ability towards zooplankton prey. Both at the individual and population levels, gill raker number was correlated with pelagic niche use and the size of utilized zooplankton prey. Furthermore, the average body size and the abundance and diversity of the zooplankton community decreased with the increasing diversity of coregonids. We argue that zooplankton feeding leads to an eco-evolutionary feedback loop that may further shape the gill raker morphology since natural selection intensifies under resource competition for depleted prey communities. Eco-evolutionary interactions may thus have a central role creating and maintaining the divergence of coregonid morphs in postglacial lakes. 


\section{INTRODUCTION}

In adaptive radiation, a common ancestor is diverged into two or more species via ecological processes and morphological adaptations to utilize different niches (Schluter 2000; Grant and Grant 2008). Foraging trait evolution in relation to adaptive radiations has been intensively studied in simplified and isolated ecosystems such as distant islands or their continental counterparts, newly formed lakes (Dieckmann et al 2004; Losos and Ricklefs 2009). A classic text book example is the adaptive radiation of the beak size and shape of Geospiza spp., where a common ancestor has diversified into a variety of species specialized to feed on specific types of plant seeds within a wide range of seed sizes and hardnesses (Grant and Grant 2008). In fishes, the adaptive radiation of East African cichlids represents an excellent example of distinct morphological adaptations of head and jaws correlated with specific foraging niches (Clabaut et al 2007; Salzburger 2009). However, adaptive radiations also occur in much less diverse environments such as in many fish lineages in postglacial lakes (Schluter 1996). The general pattern is a divergence along the pelagic-benthic resource axis, where morphological adaptations in body and head shape seem to be important in the radiation process (Schluter and McPhail 1993; Robinson and Parsons 2002, Amundsen et al 2004a). We focus on one of these traits, the gill raker number, as surprisingly few large scale studies have been made to reveal the adaptive significance of this trait even though it is an important trophic trait in variety of fish species (see e.g., Janssen 1980; Gibson 1988; Friedland et al 2006).

Coregonid fishes have a circumpolar distribution with frequent co-occurrence of multiple ecologically and morphologically distinct morphs (Svärdson 1979; Bernatchez et al 1999; Amundsen et al 2004b). Both ecological and genetic evidence suggests that adaptive radiation is the most likely explanation for the observed patterns (Bernatchez 2004; Østbye et 
al 2006; Hudson et al 2007). Different morphs of coregonids have traditionally been identified from the number of gill rakers (Svärdson 1952; Lindsey 1981; Bernatchez 2004) which is a heritable and ecologically important trait (Svärdson 1979; Rogers and Bernatchez 2007). The European whitefish (Coregonus lavaretus (L.)) is the most diverse coregonid species, and have repeatedly and independently radiated from a common ancestor into multiple morphs in a large number of postglacial lakes (Østbye et al 2005). Genetic results indicated similar divergence of pelagic and littoral morphs in replicate lakes suggesting parallel evolution within each lake (Østbye et al 2006). Due to highly similar radiation patterns of morphs in different lakes, we clustered whitefish as three different groups according to their specific ecomorphology. Here, whitefish exhibit distinct morphs for all three principal lake habitats (i.e. the littoral, profundal and pelagic), in which each has specific prey resources (Kahilainen et al 2003, 2005; Jensen et al 2008). The littoral is structurally complex with diverse benthic resources, comprising a sharp contrast to the low light conditions and scanty sediment-buried benthic resources in the profundal habitat (i.e., the deep benthic zone). The pelagic zone is a structurally homogenous habitat providing zooplankton resources for fish. These principal lacustrine habitats can be considered as peaks in an adaptive landscape that requires morphological adaptations to enhance utilization of their specific diet resources. Accordingly, one should expect morphs from these principal habitats to differ in important foraging related traits such as the gill raker apparatus (Schluter and McPhail 1993; Robinson and Parsons 2002, Amundsen et al 2004a).

The trophic role of the gill raker apparatus is related to prey retention efficiency, where the gill rakers function as a cross-flow filter forcing the prey items towards the oesophagus of the fish (Sanderson et al 2001, Smith and Sanderson 2008). An increasing number of gill rakers enhance crossflow filtering and the closely spaced gill rakers also limit the escape 
possibilities of small prey, further improving the foraging efficiency. However, a dense gillraker apparatus is more likely to be clogged by sediments than more sparse gillrakers, and foraging in the muddy bottom of the profundal most likely require other gillraker adaptations than e.g. feeding on small-sized zooplankton. Accordingly, a high number of long gill rakers is common in planktivorous fish species and morphs, whereas benthic species and morphs usually display a lower number of shorter gill rakers (Janssen 1980; Schluter and McPhail 1992; Robinson and Parsons 2002). Coregonids have a wider gillraker range than other polymorphic fish lineages and thus represent an excellent candidate taxon to evaluate the significance of such phenotype-environment associations. Furthermore, the principal prey resource associated with this trait (i.e. zooplankton) can be examined in detail qualitatively and quantitatively both in the environment and the predator diet. Such comparisons in natural settings are ideal to explore the adaptive significance of the predator's functional morphology. In their seminal paper, Brooks and Dodson (1965) revealed that size selective predation of planktivorous fish alters the species composition and reduces the body size of prey communities. This has lead to a wide consensus that planktivorous fish regulates zooplankton communities (Zaret 1980; Lampert and Sommer 2007). When a proportion of fish population is adapting to a zooplankton resource, the zooplankton community response by decreased body sizes provides a feedback loop that further strengthen the selection pressure towards high foraging efficiency on small prey items. Such eco-evolutionary interactions have rarely been addressed in relation to adaptive radiations of postglacial fish.

Here, we used a set of subarctic lakes that comprises a diversity gradient of coregonid assemblages with increasing range and numbers of gill rakers, including 1) monomorphic whitefish with $c a$ 20-30 gill rakers, 2) polymorphic whitefish populations with $c a$ 15-40 rakers, and 3) polymorphic whitefish and vendace, Coregonus albula (L.) with ca 15-50 
rakers). This range constitutes a natural setting to explore the role of increasing gill raker numbers in zooplankton foraging, including the impact of coregonid radiation on zooplankton prey communities. We assumed that foraging efficiency is associated with the ability to utilize small prey, and predicted that zooplankton prey utilization is correlated to the gill raker number. Furthermore, we predicted that zooplankton size, density and community structure would change along the gradient from monomorphic to polymorphic and finally to polymorphic whitefish and vendace lakes. Such a pattern would provide an eco-evolutionary feedback mechanism where the prey community over evolutionary time (e.g. under adaptive radiation) could shape the morphology of the predator.

\section{MATERIALS AND METHODS}

\section{Study area and fish populations}

We examined a set of eight northern Fennoscandian postglacial lakes situated in the large subarctic Paatsjoki/Pasvik watercourse, including five Finnish (Lakes Aksujärvi, Vuontisjärvi, Vastusjärvi, Muddusjärvi and Paadar) and three Norwegian (Lakes Ellentjern, Tjærebukta and Skrukkebukta) lakes (Fig. 1). This set of lakes represents a wide gradient of coregonid populations. The Finnish headwater lakes discharge into the large Lake Inarijärvi (hereafter L. Inari), whereas Norwegian lakes are situated in the lower reaches of the watercourse (Fig. 1b). The study lakes are all oligotrophic (totP $3-9 \mu \mathrm{g} / 1$, totN $145-240 \mu \mathrm{g} / \mathrm{l}$ ), well-oxygenated with neutral pH-values (6.8-7.2). Surface areas range from 1 to $48 \mathrm{~km}^{2}$ and maximum depths from 7 to $73 \mathrm{~m}$ (Table 1). The ice-free season generally lasts from MayJune to October-November. Coregonids, represented by three different whitefish morphs and vendace, are the main zooplankton predators and the dominant fish species $(70-91 \%$ of numerical catches) in all lakes, except L. Ellentjern, but the composition of the coregonid assemblage differs among the lakes. 
The lakes were classified according to an increasing diversity of coregonids. Lakes Aksujärvi (hereafter L. Aksu), Ellentjern and Vuontisjärvi (L. Vuontis) were classified as type 1, with only one whitefish morph present, the large sparsely rakered (LSR) morph. LSR whitefish is identified and named according to body size and number of gill rakers, which usually ranges from approx. 20-30 (Fig. 2). In lake type 2, LSR whitefish co-exist with a densely rakered (DR) whitefish morph with approx. 30-40 gill rakers (L. Vastus) or with DR whitefish and a

small sparsely rakered (SSR) whitefish morph with approx. 15-20 gill rakers (Lakes Muddus and Paadar). In the most complex lake type 3 (Lakes Tjærebukta and Skrukkebukta), polymorphic whitefish (LSR, DR and SSR whitefish morphs) co-exist with vendace, which has the highest number of gill rakers (approx. 40-50) (Fig. 2). Vendace is a pelagic zooplankton specialist (Helland et al 2008) and does not occur naturally in the Paatsjoki/Pasvik watercourse (Amundsen et al 1999). Vendace was introduced to L. Inari in the 1950-60's and formed a very dense population during the 1980's leading to an invasion and colonization of the lower Paatsjoki lakes around 1990 (Amundsen et al 1999). As a superior planktivore competitor over DR whitefish, vendace has become the dominant fish species in the pelagic food web in many lakes in the lower parts of the Paatsjoki/Pasvik watercourse (Bøhn and Amundsen 2001; Gjelland et al 2007; Bøhn et al 2008).

\section{Fish sampling}

Sampling was conducted during September (years 2000-2007) in all the lakes. A long sampling period was needed to include several lakes and coregonid populations from both countries. This should not have any significant influence on the main patterns, since gill raker traits, habitat and diet selection of the studied coregonid populations are highly stable among different years (Amundsen et al 2004a, b; Kahilainen et al 2004, 2007, 2009). Coregonids 
were sampled from the three main habitats (littoral, pelagic and profundal) using a combination of gill net series and pelagic trawling. The Finnish lakes were sampled using a gill net set with eight nets, each having a length of $30 \mathrm{~m}$ and a height of $1.8 \mathrm{~m}$, with mesh sizes $12,15,20,25,30,35,45$ and $60 \mathrm{~mm}$ from knot to knot. In addition, we used a small pair trawl (5 $\mathrm{m}$ high, $8 \mathrm{~m}$ wide and cod-end mesh size $3 \mathrm{~mm}$ ) in the pelagic zone of these headwater lakes (see Kahilainen et al 2004 for details). In the Norwegian lakes coregonids were caught in the littoral and profundal habitats using benthic gill nets series (length $40 \mathrm{~m}$ and height $1.5 \mathrm{~m}$ ) with the mesh sizes of $10,12.5,15,18.5,22,26,35$ and $45 \mathrm{~mm}$, and in the pelagic using floating gill net series (length $40 \mathrm{~m}$ and height $6 \mathrm{~m}$ ) with mesh sizes of 8,10 , $12.5,15,18.5,22,26$ and $35 \mathrm{~mm}$.

Coregonids were field-identified to morph/species according to their overall habitus, head shape and gill rakers (Amundsen et al 2004b; Kahilainen and Østbye 2006). Minor overlap of gill raker counts exist between the whitefish morphs, but these individuals can be classified using combined information from body, head and gill rakers morphology. Uncertain SSR whitefish can be defined from LSR whitefish due to its very peculiar habitus with large eye, robust head, pronounced subterminal mouth and short bend gill rakers (Kahilainen and Østbye 2006, Harrod et al 2010). Uncertain DR whitefish was classified according to longer gill rakers, terminal mouth and pointed head shape (Amundsen et al 2004b; Harrod et al 2010). Vendace can be separated from DR whitefish accurately as it has a characteristic uppointing protruding lower jaw, very pointed head, and very long and slender gill rakers.

The number of gill rakers was counted from the first left gill arch under a preparation microscope. Stomachs were removed and prey items were identified as accurately as possible. The relative contribution of each prey category was estimated (Amundsen et al 
1996). The coregonids diet consisted of pelagic zooplankton (mainly Bosmina spp., Daphnia spp., Holopedium gibberum, calanoid and cyclopoid copepods) and benthic invertebrates (mainly molluscs, insect larvae and some benthic crustaceans). In the present study, we focused on zooplankton prey, which is the only diet category considered hereafter. Body length of up to 30 individuals of undigested zooplankton was measured from each stomach, when possible. In copepods, we measured the length from rostrum to furca and in cladocerans from head to base of the tail spine (Kahilainen et al 2005).

\section{Zooplankton sampling}

Zooplankton was sampled in September from the whole water column using two replicate samples from each lake. In the Finnish lakes, samples were taken with a Limnos-tube $(1 \mathrm{~m}$, volume $7.1 \mathrm{~L}$ ) and zooplankton net (diameter $25 \mathrm{~cm}$, mesh size $50 \mu \mathrm{m})$. Tube samples were sieved through $50 \mu \mathrm{m}$ zooplankton net and all samples were stored in 5\% formalin solution. In the Norwegian lakes, samples were taken with a 30L Schindler-Patalas trap or with a vertically hauled zooplankton net (diameter $26 \mathrm{~cm}$, mesh size $90 \mu \mathrm{m}$ ) and stored in $4 \%$ formalin solution. Differences in sampling gears between countries may have effect on zooplankton community results. The somewhat larger mesh size of zooplankton net and higher volume of Schindler-Patalas trap used in Norwegian lakes could more effective to capture larger individuals as well as higher density and diversity of zooplankton community than the smaller gear used in Finnish side (Kalff 2002). We recognize this potential bias in the interpretation of results and take this into account in prey size comparisons among coregonids. However, the smallest zooplankton found in coregonid diet $(0.30 \mathrm{~mm}, \mathrm{~B} ø \mathrm{hn}$ and Amundsen 1998) is substantially larger than the largest zooplankton net mesh sizes used in this study $(0.09 \mathrm{~mm})$, ensuring that both sampling methods have captured zooplankton sizes available to fish. Zooplankton samples were counted and measured in the laboratory, 
excluding nauplii since they were not observed in the fish diet. The body length of 30-50 randomly selected individuals from each zooplankton taxa (Bosmina, Daphnia, Calanoid and Cyclopoid copepods) was measured. The average zooplankton density per litre in the whole water column and the relative proportion of the main taxa were calculated.

\section{Statistical analyses}

At the population level, the average number of gill rakers was compared with the proportion of pelagic habitat use and diet as well as zooplankton prey size in the stomachs using Spearman correlations. The same approach was used to explore potential correlations between gill raker number and the proportion of pelagic diet and zooplankton prey size at the individual level. In individual diet data, we calibrated datasets according to the lowest samples sizes per morph/lake and then used random re-sampling for other morph/lake combinations. Differences in zooplankton prey length data among morphs/species types were harmonized by random re-sampling of 25 samples from a morphs/species within a lake when available. This approach enabled separation of effects at the individual and population levels. Differences in the zooplankton prey size among whitefish morphs and vendace were tested with analysis of covariance (ANCOVA) using the zooplankton average length in each lake as a covariate. The effect of individual gill raker number on median zooplankton prey length in the stomach was tested with a general linear model (GLM) using gill raker number, mean zooplankton length in the environment, and species/morph as predictor variables. The effect of individual gill raker number on median zooplankton prey length was finally tested with regressions within each species/morph on the full dataset, using prey length as the response and gill raker number as the predictor variable. 
A GLM was used to test for zooplankton size differences among lake types using different zooplankton taxa and lake type as categorical variables. Analysis of variance (ANOVA) was used to test for differences in the average zooplankton abundance $(\log (\mathrm{x}+1)$ transformed data) among lake types. The number of samples used for zooplankton length measurements in coregonid stomachs and in the environment was different among the lakes and we used bootstrapping for calibration of sample sizes before performing ANCOVA, GLM and ANOVA. Subsequent pairwise comparisons in these analyses were made with Tukey's HSD tests.

\section{RESULTS}

Strong positive correlations were found at the population level between the number of gill rakers and both the pelagic habitat use (Fig. $3 \mathrm{a}, \mathrm{n}=19$, Spearman correlation; $\mathrm{r}_{\mathrm{s}}=0.83, \mathrm{p}<0.01$ ) and the proportion of zooplankton in the $\operatorname{diet}$ (Fig. $3 b, n=19, r_{s}=0.84, p<0.01$ ). Polymorphic SSR and LSR whitefish populations with an average number of gill rakers from 16-21 and 22-25, respectively, mainly used the benthic niche. Monomorphic LSR whitefish populations had an average number of gill rakers from 24 to 28 and used both pelagic and benthic prey and habitat. DR whitefish had in average 33-35 gill rakers and was the most pelagic and planktivorous whitefish morph. Vendace had on average 43 gill rakers and was consistently a pelagic planktivore. In accordance with the niche utilization, a significant negative correlation was observed between the average number of gill rakers and zooplankton prey size $\left(n=19, r_{s}=-0.83, p<0.01\right)$ (Fig. 3c). The ANCOVA indicated that the average length of ingested zooplankton was dependent on coregonid morph/species $\left(F_{3,187}=91, p<0.001\right)$, but not on the observed average zooplankton length in the pelagic environment $\left(\mathrm{F}_{1,187}=2\right.$, 
$\mathrm{p}=0.13$ ). The average length of zooplankton prey gradually decreased from $1.90 \mathrm{~mm}$ in SSR whitefish, $0.95 \mathrm{~mm}$ in LSR, $0.61 \mathrm{~mm}$ in DR to $0.57 \mathrm{~mm}$ in vendace. These size differences in ingested prey were different between all coregonid taxa (Tukey's HSD tests, $p<0.001$ ), except between DR whitefish and vendace ( $\mathrm{p}=\mathrm{NS})$. At the individual level, the general patterns observed at the population level were supported by a positive correlation between the number of gill rakers and the proportion of zooplankton in diet (Fig. $4 \mathrm{a}, \mathrm{n}=48, \mathrm{r}_{\mathrm{s}}=0.68$, $\mathrm{p}<0.01)$ and a negative correlation between number of gill rakers and zooplankton prey size (Fig. 4b, $\left.n=245, r_{s}=-0.69, p<0.01\right)$. The GLM-analysis (adj. $\left.r^{2}=0.59\right)$ confirmed a strong effect of morph/species on median zooplankton prey size ( $\mathrm{P}<0.05$ for all morphs/species), and also indicated a negative effect of individual gill raker number within the morph/species $(\mathrm{p}=0.082)$. The regressions within each $\mathrm{morph} / \mathrm{species}$ revealed that the negative effect of individual gill raker number on zooplankton prey size was significant only within the LSR and SSR whitefish (Table 2).

There were distinct trends in the zooplankton community structure along the increasing coregonid diversity gradient (Fig. 5). The average size of zooplankton differed among lake types $\left(\mathrm{GLM}, \mathrm{F}_{2,1025}=67, \mathrm{p}<0.01\right)$ and gradually decreased from $0.65 \mathrm{~mm}$ in lake type $1,0.60$ $\mathrm{mm}$ in type 2 to $0.54 \mathrm{~mm}$ in lake type 3 (Tukey's HSD tests, $\mathrm{p}<0.05$ ) (Fig. 5a). A decreasing trend along the coregonid diversity gradient was observed also in zooplankton abundance (Fig. $5 b$ ), but with no statistical significance (ANOVA, $F_{2,13}=0.41, p=0.67$ ). The average density in lake type $1(8.2 \mathrm{ind} / \mathrm{l})$ tended to be higher than in lake type 2 and 3 (5.4 and 5.8 ind/1, respectively). Zooplankton community composition changed from equal proportions of copepods and cladocerans in lake type 1 to a clear dominance of cladocerans in lake type 3 (Fig. 5c). This was mainly due to a decrease in the proportion of cyclopoid copepods and an 
increase in the proportion of Daphnia spp., in particular the small-sized and transparent species D. cristata, in lake type 3 .

\section{DISCUSSION}

We documented a strong relationship between gill raker numbers and the degree of planktivory; a pattern that appears to be common in polymorphic fish populations in the northern hemisphere (Schluter and McPhail 1992, Skúlason et al 1999; Amundsen et al 2004a). The current study extended this common pattern to a much larger scale by including all principal habitat types and a very wide range of gill raker number utilizing 19 different populations. There were strong positive correlations between predator trophic morphology (gill rakers) and pelagic niche utilization (habitat and diet) as well as an adaptive significance of increasing number of gill rakers facilitating the utilization of smaller prey. The study furthermore extends the link between gill raker traits and niche utilization from the commonly occurring littoral-pelagic morph pairs of various fish species in the northern hemisphere (e.g. Schluter and McPhail 1993; Robinson \& Parsons 2002), to also include the far less explored profundal niche. The fish with the lowest gill raker numbers $(<20)$ were almost exclusively associated with the profundal habitat, the intermediate numbers (20-30) mainly with the littoral, whereas the highest numbers (whitefish: 30-40; vendace $>40$ ) were associated with the pelagic habitat and a typical zooplanktivore niche. These phenotypeenvironment correlations proved to be strong both at the individual and population levels, suggesting that gill raker trait divergence is central in adaptive radiation of whitefish between these three principal habitats of subarctic lakes. 
The number of gill rakers is a single heritable trait in coregonid fishes (Svärdson 1979; Rogers and Bernatchez 2007), but apparently it also effectively captures much of other morphological traits. Several trophic traits (i.e. head and body morphology) are associated to fish feeding niche utilization along traditional pelagic-littoral resource axis in many postglacial fish morphs (Schluter 1996; Robinson and Parsons 2002), but very little is known about profundal adaptations. The SSR whitefish typically residing in the profundal habitat, has the lowest gill raker counts among the explored whitefish morphs and a body and head morphology that likely have an adaptive value in profundal foraging (Kahilainen and Østbye 2006). Similar adaptations in trophic related traits were shown to be heritable in a profundal Arctic charr morph specializing on soft bottom benthos (Klemetsen et al 2002, Knudsen et al 2006). Foraging on prey items buried in soft bottom profundal sediments requires some suction of mud (Kahilainen et al 2003). A low number of short, widely spaced gill rakers is probably sufficient to retain typical profundal prey types (i.e. Pisidium bivalves and chironomid larvae) while allowing the mud to be disposed through the gillraker slits (Kahilainen and Østbye 2006). A dense gillraker apparatus would in contrast likely be clogged by mud (Amundsen et al 2004b). The SSR whitefish mainly consumed relatively large-sized prey, suggesting a limited foraging efficiency on zooplankton. The LSR whitefish morph has intermediate numbers, length and spacing of gill rakers and subterminal mouth which likely facilitate benthic foraging (Kahilainen and Østbye 2006; Harrod et al 2010). LSR whitefish is apparently less efficient in predation of small-sized zooplankton than the specialized planktivore DR whitefish morph that has large number of long and dense gill rakers and a terminal mouth and slender body shape (Kahilainen and Østbye 2006). These morphological traits of DR whitefish are well suited for pelagic planktivores (Webb 1984) and are likely to have evolved in the absence of resource competitors like ciscoes/vendace (Bernatchez 2004; Bøhn et al 2008). 
The differences between coregonids in gill raker apparatus can be compared to the divergence of beak shape in birds, jaw shape in amphibians, mandible shape in bats or baleen plates in whales which all facilitate the use of different dietary niches (Werth 2004; Pfennig et al 2006; Price 2008, Nogueira et al 2009). In fish, there is a common trend of increasing number of gill rakers from piscivores to benthivores and finally to planktivores (Gibson 1988; Langeland and Nøst 1995). Our results on Coregonus demonstrate a similar intra-genus benthivore-planktivore trend in gill raker numbers. Our field data furthermore show a negative correlation between the number of gill rakers and zooplankton prey size both at the population and individual levels. Zooplankton prey is available in all principal lake habitats (littoral, profundal and pelagic zones), providing an opportunity for planktivory for all whitefish morphs. The gill raker apparatus functions as a crossflow filter that directs prey particles towards the oesophagus (Sanderson et al 2001), and explains why increasing number of gill rakers facilitates the retention of smaller prey sizes. Previous studies failing to find similar correlations between gill raker traits and prey size in salmonids (Seghers 1975; Sandlund et al 1987; Budy et al 2005), may not have captured the essential range of trait variation that is demonstrated among the coregonids in the present study.

The observed strong correlation between gill raker number and prey utilization at the individual level suggests a significant role of gill rakers in individual foraging efficiency that may promote disruptive selection. Adaptive evolution and divergence of trophic traits are generally linked to unequal utilization efficiency of prey resources between individuals (Knudsen et al 2007; Araújo et al 2008), which may ultimately lead to differences in fitness and promote disruptive selection that may act in the formation of new morphs (Rueffler et al 2006). In a monomorphic three-spined stickleback population, Bolnick and Lau (2008) found 
evidence for disruptive selection via intraspecific competition, as individuals with high or low gill raker counts had higher growth rates than individuals with intermediate gill raker numbers. In addition, if mating is assortative between phenotypically and ecologically similar individuals, the disruptive selection provides a pathway to population divergence into morphs (Snowberg and Bolnick 2008) and subsequently to speciation (Dieckmann and Doebeli 1999; Schluter 2000). Monomorphic LSR whitefish with intermediate number of gill rakers is the most common population type in northern Fennoscandia and probably represents the ancestral morphotype (Østbye et al 2006), since allopatric SSR or DR whitefish populations have not been found in the region (Lehtonen and Niemelä 1998; Amundsen et al 2004b). During the early colonization of these postglacial lakes, ecological opportunities have presumably been high for specialization to each of the principal habitat types and their associated prey communities. These three principal trophic niches may promote disruptive selection on gill raker traits by constituting peaks in an adaptive landscape, where each whitefish morph has adapted morphologically to utilize one of these peaks. Monomorphic LSR whitefish with intermediate gill raker number use all the principal lake habitats foraging both on zooplankton and benthic macroinvertebrates (Amundsen et al 2004b; Kahilainen et al 2007). In sympatry with other morphs (i.e. in polymorphic lakes) the LSR whitefish prefers littoral macroinvertebrates, whereas the SSR whitefish utilizes profundal benthos and DR whitefish zooplankton (Harrod et al 2010). Interestingly, the effect of gill raker number on zooplankton prey size was strongest in the SSR whitefish, weaker but still significant in the LSR whitefish, and with no significant effect in the DR whitefish and vendace. This suggests a directional selection towards increasing gillraker numbers for SSR and LSR whitefish individuals that utilize a planktivorous niche, whereas there seems to be little support for directional selection on increasing gill raker number in DR whitefish or vendace in these lakes. Taken collectively, our results support a scenario where LSR whitefish has diverged 
into SSR and DR whitefish morphs via disruptive selection primarily acting on gill raker morphology and foraging abilities (Østbye et al 2006).

The differences in zooplankton community structure among the three lake types suggest a general importance of gill raker numbers in relation to planktivore predation. Although the sampling was performed only in September, the previous seasonal open water datasets of zooplankton and niche utilization of whitefish morphs and vendace support the observed patterns in this study (Bøhn \& Amundsen 1998; 2001; Kahilainen et al 2004; 2005; Gjelland et al 2009). However, there is a need for winter sampling during ice cover when zooplankton community is certainly different due to lack of cladocerans (Tolonen 1998) and niche utilization of coregonids may also differ (Jurvelius and Marjomäki 2008). In this study, we found that zooplankton body size and density decreased with increasing coregonid diversity, a pattern commonly observed in zooplankton communities when the number of specialized planktivorous fish species increases (Nilsson and Pejler 1973; Post et al 2008; Amundsen et al 2009). However, this pattern has previously not been connected to adaptive radiation in postglacial fish. These zooplankton community patterns could have been even stronger, if sampling gear had been identical. The vendace-whitefish lakes (lake type 3) were sampled using larger zooplankton gear that may have increased the average length of zooplankton. In lakes with only LSR whitefish present the competition for zooplankton resources in the pelagic habitat is expected to be weak. Accordingly, we observed large body size, high density and wide diversity of zooplankton in these lakes. In lakes including DR whitefish, however, increased competition for zooplankton was indicated by reduced body size, density and availability of zooplankton. Under such conditions, the frequency of planktivory in the LSR whitefish is low (Amundsen et al 2004b; Kahilainen et al 2007). This trend was even more pronounced in polymorphic lakes with vendace present as both the LSR and even the 
DR whitefish morphs were forced to utilize the benthic food resources (Bøhn and Amundsen 2001; Bøhn et al 2008). Hence, in each step of increased coregonid diversity, predation efficiency for zooplankton increases and accordingly modifies the zooplankton community. Subsequently, this reduces the opportunities of SSR and LSR whitefish morphs to utilize the zooplanktivore dietary niche. We argue that this represents an eco-evolutionary process with a feedback loop that reduces the formation of intermediate phenotypes (and hybrids), and increases resource segregation among morphs. Similar feedback loops between predator morphology and resources have been found in zooplanktivore alewife Alosa pseudoharengus populations (Palkovacs and Post 2008, 2009) and in seed-feeding Geospiza finches (Grant and Grant 2008). This process is able both to create and maintain polymorphism in various ecosystems, and may over time lead to the formation of new species. Our data represent empirical support for the early stages of this process in pristine and relatively young fish communities. In a broader perspective, including the well known adaptive radiation in much older systems (like e.g. the speciation of cichlids), a profound link between ecological and evolutionary timescales is strongly indicated (see also Hairston et al 2005).

In conclusion, our study demonstrates the adaptive significance of gill rakers in foraging: an increasing number of gill rakers facilitates the utilization of smaller prey and is advantageous to planktivory, but at the same time disadvantageous to benthivory, in particular to feeding in the profundal sediments (Fig. 6). Apparently, the three principal lacustrine habitats represent adaptive peaks, promoting disruptive selection leading to gill raker divergence and polymorphism. The phenotype-environment correlations between gill raker number and pelagic niche utilization proved to be strong both at the individual and population levels. Evidently, the coregonid gill raker divergence influences the zooplankton community 
structure and likely creates an eco-evolutionary feedback loop maintaining and possibly strengthening the segregation of pelagic and benthic morphs.

\section{ACKNOWLEDGMENTS}

The authors thank the Ministry of Agriculture and Forestry, Municipality of Inari, Finnish Cultural Foundation, Ella and Georg Ehrnrooth Foundation, Otto A. Malm Foundation, Emil Aaltonen Foundation, European Regional Developmental Fund (project A30205), The Norwegian Research Council (NFR 186320/V40 and 183984/S30), Norwegian Directorate for Nature Management, The County Governor of Finnmark and Pasvik Kraft AS for funding. We also acknowledge the field and laboratory work by Aikio O., Antti-Poika P., Dalsbø L., Eloranta A., Helminen M., Johannesen K.S., Johansson K., Jääskeläinen P., Kervinen J., Lien C., Marttila J., Mäenpää K., Niemistö J., Pennanen, M., Pohtila J., Salonen, M., Sáren, J., Sohlberg K.G., Tuomaala, A. and Vatanen S. Muddusjärvi Research Station kindly provided facilities during the field sampling. We like to thank White E. and AnttiPoika P. for line illustrations and Malinen T. for comments on manuscript.

\section{REFERENCES}

Amundsen P-A, Gabler HM, Staldvik FJ (1996) A new approach to graphical analysis of feeding strategy from stomach contents data- modification of Costello (1990) method. J Fish Biol 48:607-614

Amundsen P-A, Bøhn T, Våga GH (2004a) Gill raker morphology and feeding ecology of two sympatric morphs of European whitefish (Coregonus lavaretus). Ann Zool Fenn 41:291-300 
Amundsen P-A, Knudsen R, Klemetsen A, Kristoffersen R (2004b) Resource competition and interactive segregation between sympatric whitefish morphs. Ann Zool Fenn 41:301307

Amundsen P-A, Siwertsson A, Primicerio R, Bøhn T (2009) Long-term responses of zooplankton to invasion by a planktivorous fish in a subarctic watercourse. Freshw Biol $54: 24-34$

Amundsen P-A, Staldvik FJ, Reshetnikov YS, Kashulin N, Lukin A, Bøhn T, Sandlund OT, Popova OA (1999) Invasion of vendace Coregonus albula in a subarctic watercourse. Biol Cons 88:405-413

Araújo MS, Guimarães, PR, Svanbäck R, Pinheiro A, Guimarães P, dos Reis SF, Bolnick DI (2008) Network analysis reveals contrasting effects of intraspecific competition on individual vs. population diets. Ecology 89:1981-1993

Bernatchez L (2004) Ecological theory of adaptive radiation: empirical assessment from Coregonine fishes (Salmoniformes). In: Hendry AP and Stearns SC (eds) Evolution illuminated: salmon and their relatives. Oxford University Press, Oxford, pp 175-207

Bernatchez L, Chouinard A, Lu G (1999) Integrating molecular genetics and ecology in studies of adaptive radiation: whitefish, Coregonus sp., as a case study. Biol J Linn Soc $68: 173-194$

Bolnick DI, Lau OL (2008) Predictable patterns of disruptive selection in stickleback in postglacial lakes. Am Nat 172:1-11

Brooks JL, Dodson SI (1965) Predation, body size, and composition of plankton. Science $150: 28-35$

Budy P, Haddix T, Scheidervin R (2005) Zooplankton size selection relative to gill raker spacing in rainbow trout. Trans Am Fish Soc 134:1228-1235 
Bøhn T, Amundsen P-A (1998) Effects of invading vendace (Coregonus albula L.) on species composition and body size in two zooplankton communities of the Pasvik River System, northern Norway. J Plankton Res 20:243-256

Bøhn T, Amundsen P-A (2001) The competitive edge of an invading specialist. Ecology $82: 2150-2163$

Bøhn T, Amundsen P-A, Sparrow A (2008) Competitive exclusion after invasion? Biol Inv $10: 359-368$

Clabaut C, Bunje PME, Salzburger W, Meyer A (2007) Geometric morphometric analyses provide evidence for the adaptive character of the Tanganyikan cichlid fish radiations. Evolution 61:560-578

Dieckmann U, Doebeli M (1999) On the origin of species by sympatric speciation. Nature $400: 354-357$

Dieckman U, Doebeli M, Metz JAJ, Tautz D (eds) (2004) Adaptive Speciation. Cambridge University Press, Cambridge

Friedland KD, Ahrenholz DW, Smith JW, Manning M, Ryan J (2006) Sieving functional morphology of the gill raker feeding apparatus of Atlantic menhaden. J Exp Zool 305A:974-985

Gibson RN (1988) Development, morphometry and particle retention capability of gill rakers in the herring, Clupea harengus L. J Fish Biol 32:949-962

Gjelland KØ, Bøhn T, Amundsen P-A (2007) Is coexistence mediated by microhabitat segregation? - an in-depth exploration of a fish invasion. J Fish Biol 71 (Suppl. D):196209

Gjelland KØ, Bøhn T, Horne JK, Jensvoll I, Knudsen FR, Amundsen P-A (2009) Planktivore vertical migration and shoaling under a subarctic light regime. Can J Fish Aquat Sci 66:525-539 
Grant PR, Grant BR (2008) How and why species multiply? The radiation of Darwin's Finches. Princeton University Press, New Jersey

Hairston Jr NG, Ellner SP, Geber MA, Yoshida T, Fox JA (2005) Rapid evolution and the convergence of ecological and evolutionary time. Ecol Lett 8:1114-1127

Harrod C, Mallela J, Kahilainen KK (2010) Phenotype-environment correlations and character displacement in a putative fish radiation. $\mathrm{J}$ Anim Ecol (in press)

Helland, IP, Harrod C, Freyhof J, Mehner T (2008) Co-existence of a pair of pelagic planktivorous coregonid fishes. Evol Ecol Res 10:373-390

Hudson AG, Vonlanthen P, Müller R, Seehausen O (2007) Review: The geography of speciation and adaptive radiation of coregonines. Arch Hydrob Spec Iss Adv Limnol 60:111-146

Janssen J (1980) Alewives (Alosa pseudoharengus) and ciscoes (Coregonus artedii) as selective and non-selective planktivores. In: Kerfoot WC (ed) Evolution and ecology of zooplankton communities., University Press of New England, New Hampshire, pp 580586

Jensen H, Kahilainen KK, Amundsen P-A, Gjelland KØ, Tuomaala A, Malinen T, Bøhn T (2008) Predation by brown trout (Salmo trutta) along a diversifying prey community gradient. Can J Fish Aquat Sci 65:1831-1841

Jurvelius J, Marjomäki TJ (2008) Night, day, sunrise, sunset: do fish under snow and ice recognize the difference? Freshw Biol 53:2287-2294

Kahilainen K, Alajärvi E, Lehtonen H (2005) Planktivory and diet-overlap of densely rakered whitefish (Coregonus lavaretus (L.)) in a subarctic lake. Ecol Freshw Fish 14:50-58

Kahilainen K, Lehtonen H, Könönen K (2003) Consequence of habitat segregation to growth rate of two sparsely rakered whitefish (Coregonus lavaretus (L.)) forms in a subarctic lake. Ecol Freshw Fish 12:275-285 
Kahilainen K, Malinen T, Tuomaala A, Lehtonen H (2004) Diel and seasonal habitat and food segregation of three sympatric whitefish (Coregonus lavaretus (L.)) forms in a subarctic lake. J Fish Biol 64:418-434

Kahilainen K, Malinen T, Lehtonen H (2009) Polar light regime and piscivory govern diel vertical migrations of planktivorous fish and zooplankton in a subarctic lake. Ecol Freshw Fish 18:481-490

Kahilainen K, Østbye K (2006) Morphological differentiation and resource polymorphism in three sympatric whitefish Coregonus lavaretus (L.) forms in a subarctic lake. J Fish Biol $68: 63-79$

Kahilainen KK, Malinen T, Tuomaala A, Alajärvi E, Tolonen A, Lehtonen H (2007) Empirical evaluation of phenotype-environment correlation and trait utility with allopatric and sympatric whitefish (Coregonus lavaretus (L.)) populations in subarctic lakes. Biol J Linn Soc 92:561-572

Kalff J (2002) Limnology. Prentice-Hall, New Jersey

Klemetsen A, Elliott JM, Knudsen R, Sørensen P (2002) Evidence for genetic differences in the offspring of two sympatric morphs of Arctic charr. J Fish Biol 60:933-950

Knudsen R, Amundsen P-A, Primicerio R, Klemetsen A, Sørensen P (2007) Contrasting niche-based variation in trophic morphology within Arctic charr populations. Evol Ecol Res 9:1005-1021

Knudsen R, Klemetsen A, Amundsen P-A, Hermansen B (2006) Incipient speciation through niche expansion: an example from the Arctic charr in a subarctic lake. Proc Roy Soc B $273: 2291-2298$

Lampert W, Sommer U (2007) Limnoecology. 2nd edn. Oxford University Press, Oxford Langeland A, Nøst T (1995) Gill raker structure and selective predation on zooplankton by particulate feeding fish. J Fish Biol 47:719-732 
Lehtonen H, Niemelä E (1998) Growth and population structure of whitefish (Coregonus lavaretus (L.)) in mountain lakes of northern Finland. Arch Hydrobiol Spec Iss Adv Limnol 49:81-95

Lindsey CC (1981) Stock's are chameleons: plasticity in gill rakers of Coregonid fishes. Can J Fish Aquat Sci 38:1497-1506

Losos JB, Ricklefs RE (2009) Adaptation and diversification on islands. Nature 457:830-836

Nilsson N-A, Pejler B (1973) On the relation between fish fauna and zooplankton composition in north Swedish lakes. Rep Inst Freshw Res Drott 53:51-77

Nogueira MR, Peracchi AL, Monteiro LR (2009) Morphological correlates of bite force and diet in the skull and mandible of phyllostomid bats. Func Ecol 23:715-723

Østbye K, Bernatchez L, Næsje TF, Himberg M, Hindar K (2005) The evolutionary history of European whitefish (Coregonus lavaretus L.) as inferred from mtDNA phylogeography and gillraker numbers. Mol Ecol 14:4371-4387

Østbye K, Amundsen P-A, Bernatchez L, Klemetsen A, Knudsen R, Kristoffersen R, Næsje TF, Hindar K (2006) Parallel evolution of ecomorphological traits in the European whitefish Coregonus lavaretus (L.) species complex during postglacial times. Mol Ecol $15: 3983-4001$

Palkovacs EP, Post DM (2008) Eco-evolutionary interactions between predators and prey: can predator-induced changes to prey communities feed back to shape predator foraging traits. Evol Ecol Res 10: 699-720

Palkovacs EP, Post DM (2009) Experimental evidence that phenotypic divergence in predators drives community divergence in prey. Ecology 90: 300-305

Pfennig DW, Rice AM, Martin RA (2006) Ecological opportunity and phenotypic plasticity interact to promote character displacement and species coexistence. Ecology 87:769-779 
Post DM, Palkovacs EP, Schielke EG, Dodson SI (2008) Intraspecific variation in a predator affects community structure and cascading trophic interactions. Ecology 89:2019-2032

Price T (2008) Speciation in birds. Roberts and Company Publishers, Colorado

Robinson BW, Parsons KJ (2002) Changing times, spaces, and faces: tests and implications of adaptive morphological plasticity in the fishes of northern postglacial lakes. Can J Fish Aquat Sci 59:1819-1833

Rogers SM, Bernatchez L (2007) The genetic architecture of ecological speciation and the association with signatures of selection in natural lake whitefish (Coregonus sp. Salmonidae) species pairs. Mol Biol Evol 24: 1423-1438

Rueffler C, Van Dooren TJM, Leimar O, Abrams PA (2006) Disruptive selection and then what? TREE 21:238-245

Salzburger W (2009) The interaction of sexually and naturally selected traits in the adaptive radiations of cichlid fishes. Mol Ecol 18:169-185

Sanderson SL, Cheer AY, Goodrich JS, Graziano JD, Callan WT (2001) Crossflow filtration in suspension-feeding fishes. Nature 412:439-441

Sandlund OT, Næsje TF, Kjellberg G (1987) The size selection of Bosmina longispina and Daphnia galeata by co-occuring cisco (Coregonus albula), whitefish (C. lavaretus) and smelt (Osmerus eperlanus). Arch Hydrobiol 110:357-363

Schluter D (1996) Ecological speciation in postglacial fishes. Phil Trans R Soc Lond B $351: 807-814$

Schluter D (2000) The ecology of adaptive radiation. Oxford University Press, Oxford

Schluter D, McPhail JD (1992) Ecological character displacement and speciation in sticklebacks. Am Nat 140:85-108

Schluter D, McPhail JD (1993) Character displacement and replicate adaptive radiation. TREE 8:197-200 
Seghers BH (1975) Role of gill rakers in size-selective predation by lake whitefish, Coregonus clupeaformis (Mitchill). Verh Int Verein Limnol 19:2401-2405

Skúlason S, Snorrason S, Jónsson B (1999) Sympatric morphs, populations and speciation in freshwater fish with emphasis on arctic charr. In: Magurran AE, May RM (eds) Evolution of biological diversity. Oxford University Press, Oxford, pp 70-92

Smith JC, Sanderson SL (2008) Intra-oral flow patterns and speeds in a suspension-feeding fish with gill rakers removed versus intact. Biological Bulletin 215:309-318

Snowberg LK, Bolnick DI (2008) Assortative mating by diet in a phenotypically unimodal but ecologically variable population of stickleback. Am Nat 172:733-739

Svärdson G (1952) The coregonid problem. IV. The significance of scales and gillrakers. Rep Inst Freshw Res Drott 33:141-166

Svärdson G (1979) Speciation of Scandinavian Coregonus. Rep Inst Freshw Res Drott 57:195

Tolonen A (1998) Application of a bioenergetics model for analysis of growth and food consumption of subarctic whitefish Coregonus lavaretus (L.) in Lake Kilpisjärvi, Finnish Lapland. Hydrobiologia 390:153-169

Webb PW (1984) Form and function in fish swimming. Sci Am 251:58-68

Werth AJ (2004) Models of hydrodynamic flow in the bowhead whale filtering apparatus. J Exp Biol 207:3569-3580

Zaret TM (1980) Predation and freshwater communities. Yale University Press, London 


\section{FIGURE CAPTIONS}

Fig. 1. Map of (a) the northern Fennoscandia and (b) Paatsjoki/Pasvik watercourse. Study lakes with lake type definition indicated in the parenthesis $(1=$ monomorphic whitefish, $2=$ polymorphic whitefish and 3=polymorphic whitefish and vendace).

Fig. 2. Combined gill raker distributions of whitefish morphs ( $\mathrm{SSR}=$ small sparsely rakered, $\mathrm{LSR}=$ large sparsely rakered, $\mathrm{DR}=$ densely rakered) and vendace in study lakes. Line illustrations present the first left gill arch and gill raker morphology of different whitefish morphs.

Fig. 3. Correlations between gill raker number and (a) the proportion of pelagic habitat use, (b) the proportion of zooplankton in the diet and (c) the zooplankton prey size at the population level. Population types are marked with different labels: SSR whitefish (circle), LSR whitefish (triangle), DR whitefish (square) and vendace (diamond).

Fig. 4. Individual level correlations between gill raker number and (a) the proportion of zooplankton in the diet and (b) the average zooplankton prey size. Population types are marked with different labels: SSR whitefish (circle), LSR whitefish (triangle), DR whitefish (square) and vendace (diamond).

Fig. 5. Zooplankton (a) body length, (b) density and (c) community composition along an increased diversity gradient of coregonids (lake types: 1=monomorphic whitefish, 2=polymorphic whitefish and 3=polymorphic whitefish and vendace). Zooplankton taxa indicated in bars are Bosmina spp. (white), Daphnia spp. (grey), Holopedium gibberum (black), Calanoid (vertical hatching) and Cyclopoid copepods (diamond hatching). In lake type 3, Daphnia spp. refers mainly to Daphnia cristata.

Fig. 6. Ecomorphological gradient of studied coregonid populations. Whitefish morphs ( $\mathrm{SSR}=$ small sparsely rakered, $\mathrm{LSR}=$ large sparsely rakered, $\mathrm{DR}=$ densely rakered) and vendace body shapes are illustrated with line drawings. Normal distributions illustrate 
niche widths and accompanying text indicates main habitat, diet and ecological classification of different coregonids. Lowest arrow indicates increasing morphological specialization towards zooplanktivory. 
Table 1. Background data on location, morphometry, water chemistry and fish fauna of the study lakes. Coregonids and other fish species present in the study lakes are indicated with abbreviations. Lake type refers to the diversity of coregonid fish communities (1=monomorphic whitefish, 2=polymorphic whitefish, 3=polymorphic whitefish and vendace).

\begin{tabular}{|c|c|c|c|c|c|c|c|c|}
\hline Parameter & $\begin{array}{l}\text { Lake } \\
\text { Aksu }\end{array}$ & $\begin{array}{l}\text { Lake } \\
\text { Ellentjern }\end{array}$ & $\begin{array}{l}\text { Lake } \\
\text { Vuontis }\end{array}$ & $\begin{array}{l}\text { Lake } \\
\text { Vastus }\end{array}$ & $\begin{array}{l}\text { Lake } \\
\text { Muddus }\end{array}$ & $\begin{array}{l}\text { Lake } \\
\text { Paadar }\end{array}$ & $\begin{array}{l}\text { Lake } \\
\text { Skrukkebukta }\end{array}$ & $\begin{array}{l}\text { Lake } \\
\text { Tjærebukta }\end{array}$ \\
\hline Lake type & 1 & 1 & 1 & 2 & 2 & 2 & 3 & 3 \\
\hline Latitude $\left({ }^{\circ} \mathrm{N}\right)$ & $69^{\circ} 33^{\prime}$ & $69^{\circ} 20^{\prime}$ & $69^{\circ} 01^{\prime}$ & $69^{\circ} 03^{\prime}$ & $69^{\circ} 00^{\prime}$ & $68^{\circ} 52^{\prime}$ & $69^{\circ} 33^{\prime}$ & $69^{\circ} 13^{\prime}$ \\
\hline Longitude $\left({ }^{\circ} \mathrm{E}\right)$ & $26^{\circ} 53^{\prime}$ & $20^{\circ} 49^{\prime}$ & $27^{\circ} 04^{\prime}$ & $27^{\circ} 07^{\prime}$ & $26^{\circ} 50^{\prime}$ & $26^{\circ} 35^{\prime}$ & $30^{\circ} 70^{\prime}$ & $29^{\circ} 14^{\prime}$ \\
\hline $\begin{array}{l}\text { Surface area } \\
\left(\mathrm{km}^{2}\right)\end{array}$ & 4 & 1 & 11 & 4 & 48 & 21 & 7 & 15 \\
\hline $\begin{array}{l}\text { Altitude } \\
\text { (m.a.s.l.) }\end{array}$ & 206 & 71 & 151 & 146 & 146 & 144 & 21 & 52 \\
\hline Max depth (m) & 10 & 7 & 31 & 15 & 73 & 56 & 38 & 30 \\
\hline Mean depth (m) & 3.5 & 2.5 & 6.5 & 2.7 & $8.5^{*}$ & 11.7 & 14 & 4 \\
\hline Secchi depth (m) & 2.5 & 4.5 & 8 & 2 & 3 & $6^{*}$ & $4-5.5$ & $3-4.5$ \\
\hline $\mathrm{pH}$ & - & 6.9 & $7.2^{*}$ & 7.0 & $7.2 *$ & $7.1^{*}$ & 6.9 & 6.8 \\
\hline Tot $\mathrm{P}(\mu \mathrm{g} / \mathrm{l})$ & - & 3 & $7 *$ & 7 & $5^{*}$ & $6^{*}$ & 7 & 9 \\
\hline Tot $N(\mu \mathrm{g} / \mathrm{l})$ & - & 165 & $170 *$ & 240 & $160 *$ & $160 *$ & 156 & 145 \\
\hline $\begin{array}{l}\text { Coregonid } \\
\text { proportion (\%) }\end{array}$ & 81 & 39 & 90 & 70 & 86 & 91 & 85 & 78 \\
\hline $\begin{array}{l}\text { Species/ } \\
\text { morphs present }\end{array}$ & $\begin{array}{l}\mathrm{b}, \mathrm{f}, \mathrm{g}, \mathrm{i}, \mathrm{j}, \\
\mathrm{k}, \mathrm{l}, \mathrm{m}\end{array}$ & $\mathrm{b}, \mathrm{g}, \mathrm{i}, \mathrm{j}, \mathrm{k}, \mathrm{l}$ & $\begin{array}{l}\text { b,f,g,h,i, } \\
\text { j,k,l,m }\end{array}$ & $\begin{array}{l}\mathrm{a}, \mathrm{b}, \mathrm{f}, \mathrm{g}, \mathrm{h}, \mathrm{i} \\
\mathrm{j}, \mathrm{k}, \mathrm{l}, \mathrm{m}\end{array}$ & $\begin{array}{l}\text { a,b,c,e,f,g, } \\
\text { h,i,j,k,l,m }\end{array}$ & $\begin{array}{l}\mathrm{a}, \mathrm{b}, \mathrm{c}, \mathrm{f}, \mathrm{g} \\
\mathrm{h}, \mathrm{i}, \mathrm{j}, \mathrm{k}, \mathrm{l} \\
\mathrm{,m}\end{array}$ & $\begin{array}{l}\mathrm{a}, \mathrm{b}, \mathrm{c}, \mathrm{d}, \mathrm{f}, \mathrm{g}, \\
\mathrm{i}, \mathrm{j}, \mathrm{k}, \mathrm{l}, \mathrm{m}\end{array}$ & $\begin{array}{l}\text { a,b,c,d,f,g, } \\
\mathrm{i}, \mathrm{j}, \mathrm{k}, \mathrm{l}, \mathrm{m}\end{array}$ \\
\hline
\end{tabular}

Note: *, Data from Lapland Regional Environment Centre; a, DR whitefish; b, LSR

whitefish, c, SSR whitefish; d, vendace; e, arctic charr; f, grayling; g, minnow; h, threespined stickleback; i, nine-spined stickleback; j, perch; k, pike; 1, burbot; m, brown trout. 
Table 2. Results from the regression model prey length $($ in $\mathrm{mm})=$ constant $(a)+$ gill raker number $(G r n)$. Level of significance $(\mathrm{P})$ is included for constant, gill raker number and overall model. Zooplankton length in the environment was initially included in the models, but removed from all as it had no significant contribution.

\begin{tabular}{lccccccc}
\hline Species/morph & $a$ & $\mathrm{P}(a)$ & Grn & $\mathrm{P}($ Grn $)$ & adj. $\mathrm{r}^{2}$ & $\mathrm{P}$ (overall) & $\mathrm{n}$ \\
\hline SSR & 2.9 & $<0.001$ & -0.052 & 0.002 & 0.1 & 0.002 & 88 \\
LSR & 2.3 & $<0.002$ & -0.043 & 0.007 & 0.03 & 0.007 & 212 \\
DR & 0.23 & 0.46 & 0.011 & 0.24 & 0.001 & 0.24 & 331 \\
Vendace & 0.8 & 0.017 & -0.007 & 0.22 & 0.18 & 0.22 & 6 \\
\hline
\end{tabular}




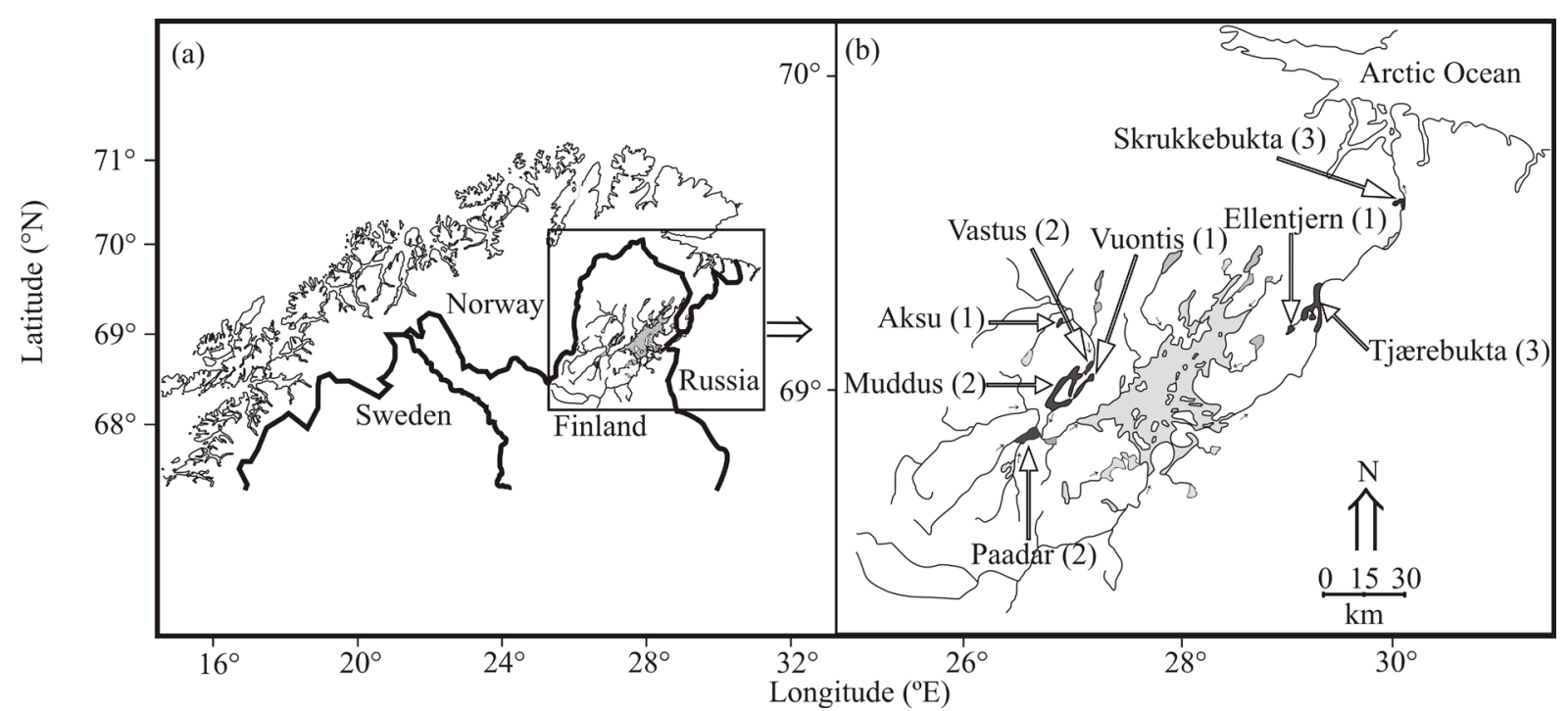

Figure 1. 


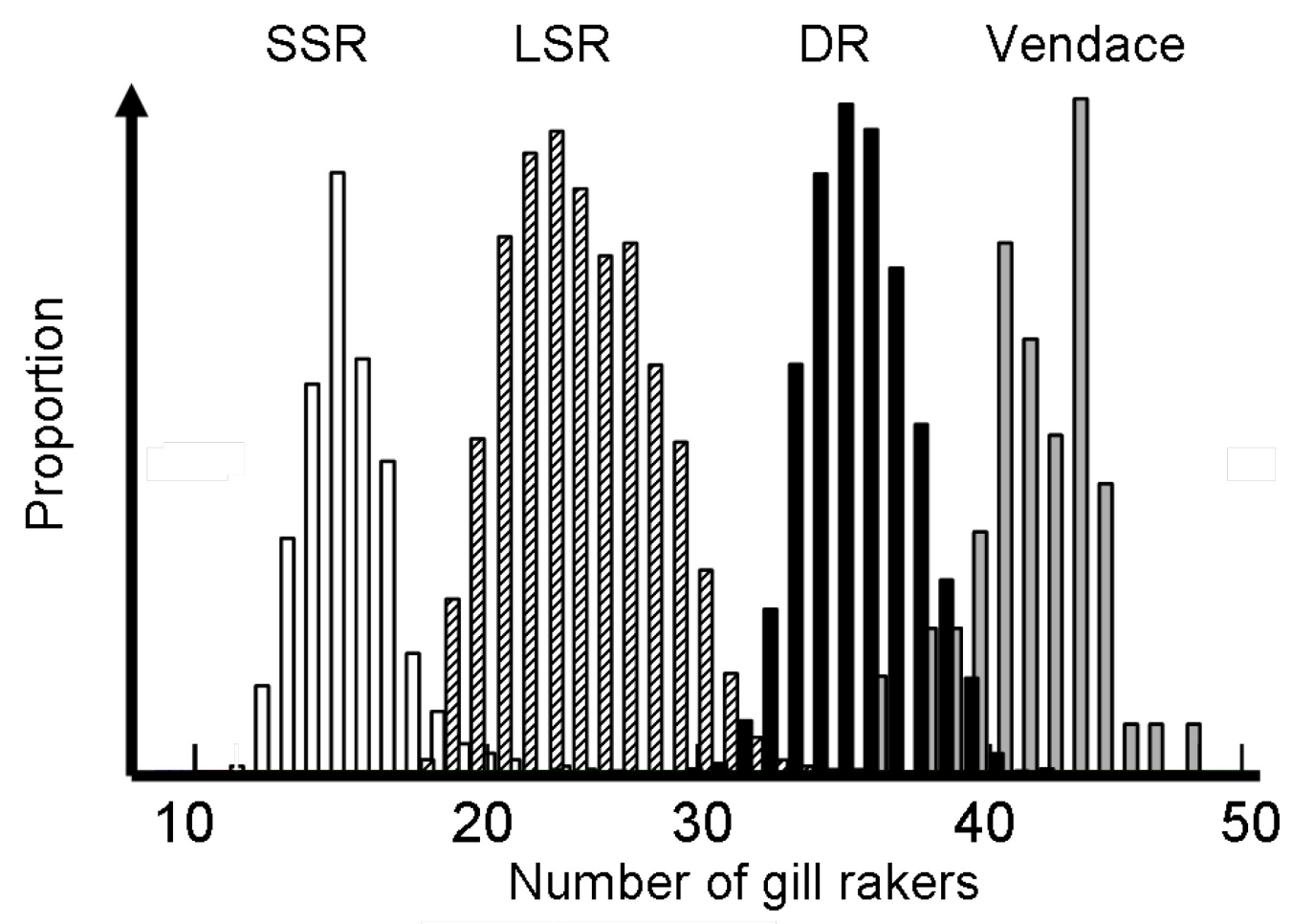

Figure 2. 

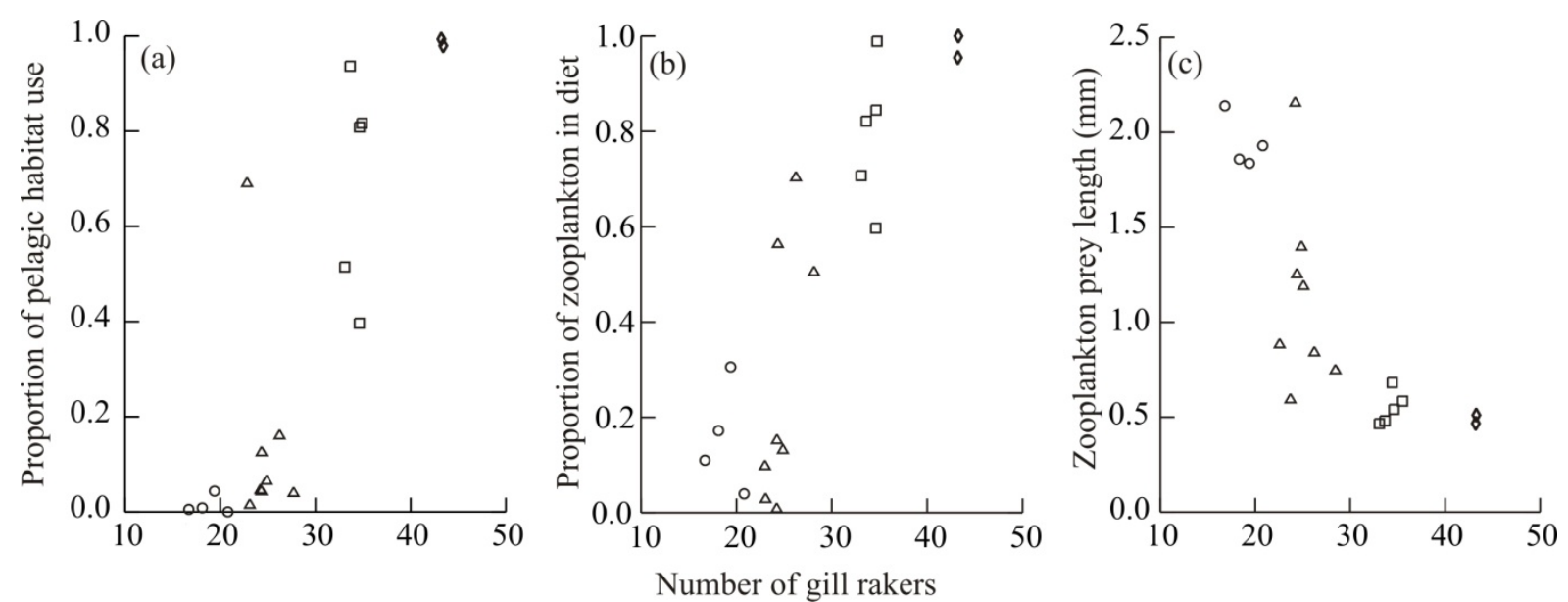

Figure 3. 


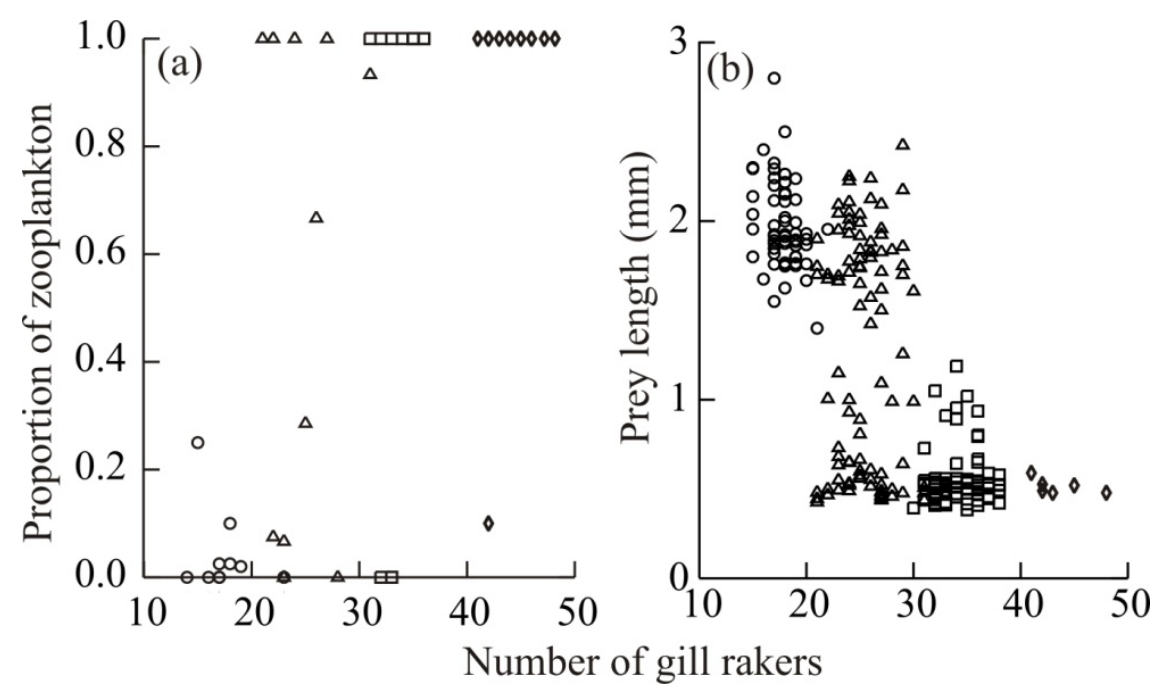

Figure 4. 


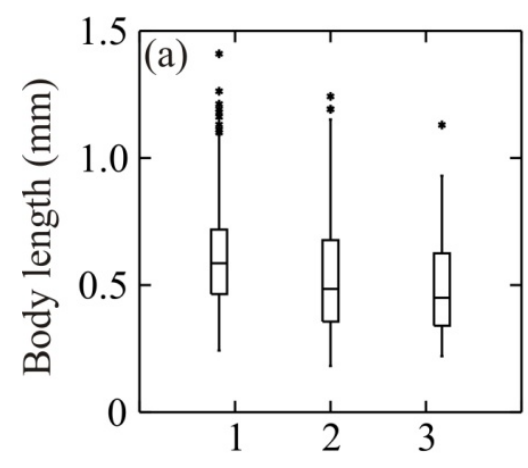

Figure 5.
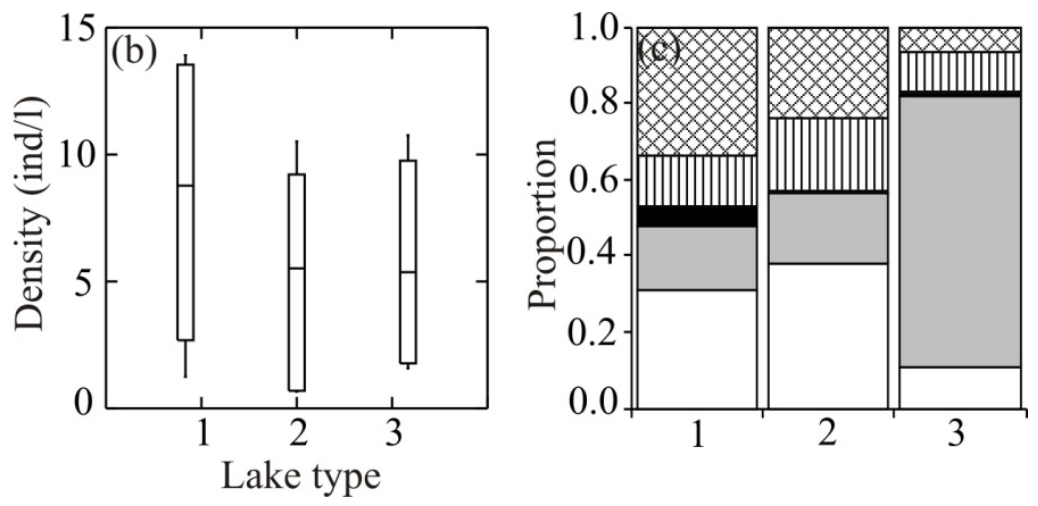


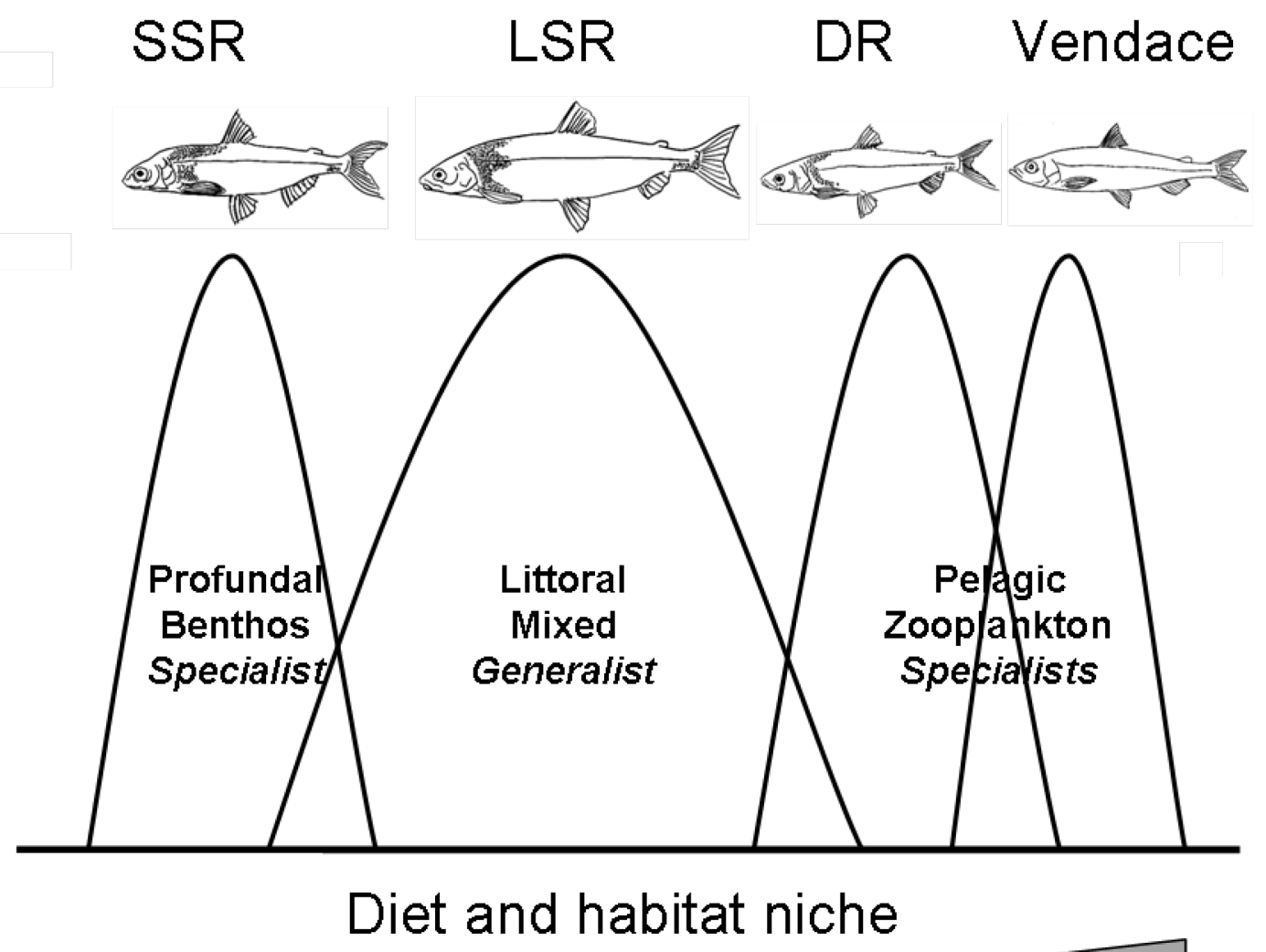

Amount of gill rakers and planktivory

Figure 6. 